\title{
Pressurized Inhalation, Suspension Dosage Form
}

National Cancer Institute

\section{Source}

National Cancer Institute. Pressurized Inhalation, Suspension Dosage Form. NCI

Thesaurus. Code C149868.

Liquid, usually multidose preparation consisting of a suspension intended for inhalation use. The preparation is presented in a pressurized container fitted with a metering dose valve. 